\title{
Enzymatic Hydrolysis and Fermentation of Banana Pseudostem Hydrolysate to Produce Bioethanol
}

\author{
Lesetja Moraba Legodi $(\mathbb{D}$, Daniel Coenrad LaGrange $(\mathbb{D}$, \\ Elbert Lukas Jansen van Rensburg $\mathbb{D}$, and Ignatious Ncube
}

\begin{abstract}
University of Limpopo, Department of Biochemistry, Microbiology and Biotechnology, Private Bag X 1106,
\end{abstract} Sovenga 0727, South Africa

Correspondence should be addressed to Lesetja Moraba Legodi; lgdles09@gmail.com

Received 25 January 2021; Revised 11 June 2021; Accepted 5 July 2021; Published 14 July 2021

Academic Editor: Diriba Muleta

\begin{abstract}
Copyright $\odot 2021$ Lesetja Moraba Legodi et al. This is an open access article distributed under the Creative Commons Attribution License, which permits unrestricted use, distribution, and reproduction in any medium, provided the original work is properly cited.

Banana pseudostem (BPS) is an agricultural waste with a high holocellulose content, which, upon hydrolysis, releases fermentable sugars that can be used for bioethanol production. Different pretreatment methods, namely, $3 \%(\mathrm{w} / \mathrm{v}) \mathrm{NaOH}, 5 \%(\mathrm{v} / \mathrm{v}) \mathrm{H}_{2} \mathrm{SO}_{4}$, and liquid hot water, applied on the BPS resulted in the availability of $52 \%, 48 \%$, and $25 \%$ cellulose after treatment, respectively. Saccharification of the pretreated BPS with $10 \mathrm{FPU} / \mathrm{g}$ dry solids $(29.3 \mathrm{mg}$ protein $/ \mathrm{g}$ d.s) crude enzyme from Trichoderma harzianum LMLBP07 $13-5$ at $50^{\circ} \mathrm{C}$ and a substrate loading of 10 to $15 \%$ released 3.8 to $21.8 \mathrm{~g} / \mathrm{L}$ and from T. longibrachiatum LMLSAUL 14-1 released 5.4 to $43.5 \mathrm{~g} / \mathrm{L}$ glucose to the biomass. Ethanol was produced through separate hydrolysis and fermentation (SHF) of alkaline pretreated BPS hydrolysate using Saccharomyces cerevisiae UL01 at $30^{\circ} \mathrm{C}$ and $100 \mathrm{rpm}$. Highest ethanol produced was $17.6 \mathrm{~g} / \mathrm{L}$. Banana pseudostem was shown as a potentially cheap substrate for bioethanol production.
\end{abstract}

\section{Introduction}

The production of first-generation bioethanol using grain or vegetable oil for biodiesel is faced with challenges due to competition with food production, particularly in developing countries [1]. Due to the direct impact sugar-rich feedstocks have on food prices, it has become imperative for future biofuel expansion to be based on the use of lignocellulosic biomass, a second-generation feedstock [2]. Lignocellulosic biomass comprises forestry, agroindustrial, and food waste and is renewable, available in excess, and inexpensive [3]. Agroindustrial residues are obtained after harvesting [4]. Lignocellulose mainly consists of sugar polymers (i.e., cellulose and hemicellulose) and lignin. The use of these polymers for the production of value-added products, such as biofuel, food additives, organic acids, and enzymes, can remediate environmental problems attributed to waste accumulation [3].

Cellulose polymer contains amorphous and crystalline regions and naturally exists in its crystalline form, which renders its resistance to enzymatic hydrolysis and therefore yields low concentrations of monosaccharide sugars. The crystalline form of cellulose is produced when several cellulose chains are held together by covalent bonds, hydrogen bonds, and van der Waals forces forming microfibrils. These microfibrils are bundled together to form cellulose fibres, making cellulose an ultrastructure [5]. Hemicellulose is the second most abundant polymeric carbohydrate in plant materials and renewable carbon with the potential to be converted into liquid fuels and chemicals. Hemicelluloses are heterogeneous polymers, which are easily hydrolysed by acids to their monomeric components made up of pentoses (D-xylose and D-arabinose), hexoses (D-glucose, D-mannose, and D-galactose), and sugar acids [6]. Lignin is the third plant polymer that provides the flexibility and strength required by plants. Lignin is an aromatic and hydrophobic polymer synthesised from one, two, or three different phenylpropanoids, namely, $p$-coumaryl alcohol ( $p$-hydroxyphenyl propanol), sinapyl alcohol (syringyl propanol), and coniferyl alcohol (guaiacyl propanol), which are singly 
derived from the amino acid phenylalanine through enzymatic processes [7].

Due to the nature and structure of cellulose in plants, including herbaceous plants, the release of fermentable sugars poses challenges $[8,9]$. Pretreatment step is necessary to overcome the recalcitrance of biomass and make the polymers available for subsequent hydrolysis and fermentation [10]. By definition, pretreatment is a prehydrolysis step that exposes cellulose fibres and makes it susceptible to enzymatic hydrolysis (breaking down of cellulose to fermentable sugars) before fermentation of the sugars released $[11,12]$. The efficiency of pretreatment is influenced by the methods used and the nature and composition of the lignocellulosic feedstock [13]. The pretreatment of lignocellulosic biomass, which can be done through the use of chemical, physical/mechanical, biological, and physicochemical or combination of methods, enables the biomass to be porous and easily accessible for microbial growth in SSF and susceptible to enzymatic hydrolysis. The hydrolysis reaction increases the production of fermentable sugars that can be converted through biochemical activities of fermenting microorganisms into ethanol [14]. Currently, the amount of cellulases required for hydrolysis (i.e., saccharification) and the low ethanol yield are key factors affecting the overall cost of producing bioethanol [15].

Physical pretreatment involves particle size reduction by milling or grinding in order to improve enzymatic hydrolysis. Chemical pretreatment methods use acid or alkaline solutions. Acid hydrolysis is one of the most promising methods, usually performed with mineral acids, but other organic acids and sulphur dioxide may be used. It results in high recovery of hemicellulosic sugars in the pretreatment liquid and in a solid cellulose fraction with enhanced enzymatic convertibility [16]. Liquid hot water (LHW) is an environmentally friendly approach in which water in the liquid phase is used to pretreat lignocellulosic biomass. It is a relatively mild pretreatment method that does not require any catalysts and does not cause significant corrosion problems on the reactor. The solubilisation of hemicellulose is catalysed by hydronium ions resulting from water autoionization [16]. Alkaline treatment is efficient for removing lignin and increases the digestibility of cellulose. Compared to acid and LHW, mild alkaline pretreatments lead to less solubilisation of hemicelluloses and less formation of inhibitory compounds, and the pretreatments can be carried out at lower temperatures [16].

Recent developments for bioeconomy establishment have recognised biorefinery as an innovative and efficient approach to fully utilise the available biomass resources for the synergistic coproduction of power, heat, and biofuels alongside food and feed ingredients, chemicals, etc., for large-scale sustainable bioeconomy [17]. Biomass feedstock is a starting material in the development of bioeconomy, and it determines the viability of any biomass processing activities, and sustainable supply of biomass is crucial to the success of bio-based economy [17]. In this study, banana pseudostem is identified as an attractive, nonedible, cellulosic feedstock suitable for bioethanol production because of its high cellulose, moderate hemicellulose, and low lignin contents. Unlike wood-based lignocellulosic biomass, the banana plant has a short life cycle, requiring only 10-14 months to bear fruits depending on the geographic location and soil type [18]. The banana plant bears fruits once in its life cycle, and for every cycle of banana production, there are four times of waste generated, higher than the harvested fruit. Banana lignocellulosic rich waste includes fruit-bunch stems, leaves, pseudostem, and rhizome $[19,20]$. After the harvesting of the banana fruit, BPS makes about $75 \%$ of the total waste generated, which is either left to rot at the local dumpsite or left to decompose in the plantation to serve as an organic soil fertiliser [20-22]. Converting BPS into reducing sugars for bioethanol production is often incomplete due to the high crystallinity of the banana cellulose fibres [13]. This study investigates different pretreatment methods on BPS, which is a source of sugars that can be used in the production of bioethanol.

\section{Materials and Methods}

2.1. Collection and Preparation of the Banana Pseudostem. Fresh BPS was cut, collected from Allesbeste farm located in Tzaneen $\left(\stackrel{\nabla}{ } 23.800943^{\circ} \mathrm{S} 30.123264^{\circ} \mathrm{E} 799 \mathrm{~m}\right.$ M1 R71 Tzaneen 0850), Limpopo Province, South Africa. The BPS was washed to remove soil and other debris using tap water. Washed BPS was cut into small pieces (approximately $20-25 \mathrm{~cm}$ in diameter and $10 \mathrm{~cm}$ in height), and the outer and core bark (pith) were separated into several blocks. The blocks and piths were dried in an oven at $65-70^{\circ} \mathrm{C}$ (Scientific, Digital model no. 276) until a constant mass. The dried BPS blocks and piths were subjected to grinding using a milling and crushing machine (Zhuans, Electric model). The ground material was sieved through a universal test sieve with an aperture size of $500 \mu \mathrm{m}$ [19]. The sieved ground particles $(<500 \mu \mathrm{m})$ were stored at room temperature $\left(20-25^{\circ} \mathrm{C}\right)$ in a sealed container until needed.

2.2. Pretreatment of the Banana Pseudostem. One hundred and fifty grams of ground BPS was suspended in each pretreatment solution, i.e., $3 \% \mathrm{NaOH}$ [23], $5 \% \mathrm{H}_{2} \mathrm{SO}_{4}$ $[13,24,25]$, and liquid hot water, LHW-autoclave, at a ratio of $1: 10$ solid : liquid. The slurries were autoclaved at $121^{\circ} \mathrm{C}$ at 15 psi for 1 hour according to Kim [26] (HL-340 Vertical Type Steam Sterilizer, Taiwan) and cooled prior to decanting and filtration of liquid through folded gauze cloth. The subsequent step was washing the insoluble solid material with tap water until the slurry reaches $\mathrm{pH}$ 7.0. The filtrate fraction from different pretreatments was analysed for sugars using high-performance liquid chromatography (HPLC). Two millimetre samples were placed in a boiling water bath for 15 minutes and subsequently centrifuged at $12,470 \times \mathrm{g}$ for 10 minutes (Beckman Coulter Microfuge ${ }^{\circledast} 16$ centrifuge). The solid material was dried in an oven at $65-70^{\circ} \mathrm{C}$ until constant mass and ground using a Waring commercial blender (model 32BL8) (Figure 1).

The ground pretreated BPS materials were stored at room temperature in a sealed container until needed. The effect of pretreatment determined by mass changes in the 


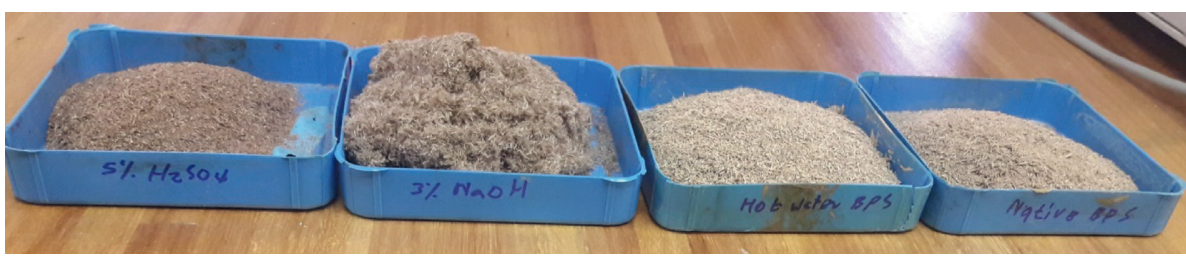

(a)

(b)

(c)

(d)

Figure 1: Banana pseudostem before and after pretreatment. (a) $5 \% \mathrm{H}_{2} \mathrm{SO}_{4}$, (b) $3 \% \mathrm{NaOH}$, (c) hot water, and (d) untreated.

BPS was done by calculating the percentage of solubilised solid material using the equation described by Matsakas et al. [27]:

$$
\text { component solubilisation }(\% \mathrm{w} / \mathrm{w})
$$

$$
=\left(\frac{w_{\text {untreated }} \times x_{\text {untreated }}-w_{\text {pretreated }} \times x_{\text {pretreated }}}{w_{\text {untreated }} \times x_{\text {untreated }}}\right) \times 100 \text {, }
$$

where $w_{\text {untreated }}$ and $w_{\text {pretreated }}$ are the dry masses of the untreated and recovered pretreated solids, respectively, and $x_{\text {untreated }}$ and $x_{\text {pretreated }}$ represent the component (cellulose, hemicellulose, and lignin) biomasses in $\% \mathrm{w} / \mathrm{w}$.

\subsection{Chemical Composition of the Banana Pseudostem.} The chemical composition of the untreated, thermo-alkali, thermo-acid, and liquid hot water (or hydrothermal) pretreated BPS samples was determined. The cellulose and lignin content was analysed by a reaction with sulphuric acid according to a standard method by TAPPI-T222 om-88, and the hemicellulose content was obtained as described in TAPPI1T19m-54 standards [28].

2.4. Fourier-Transform Infrared Spectroscopy (FTIR) of Banana Pseudostem Fibres. Fourier-transform infrared spectroscopy of untreated, thermo-alkali, thermo-acid, and hydrothermally pretreated BPS samples was performed using a Spectrum 100 FT-IR (PerkinElmer, Waltham, MA, USA) equipped with an attenuated total reflection (ATR) accessory with a diamond/ZnSe crystal (64 scans, $4 \mathrm{~cm}^{-1}$ resolution, with wavenumber range $500-4000 \mathrm{~cm}^{-1}$ ) according to Motaung and Anandjiwala [28].

2.5. Cellulase Production and Extraction. Two fungal species, namely, Trichoderma harzianum LMLUL 13-5 and Trichoderma longibrachiatum LMLUL 14-1, obtained from the University of Limpopo culture collection, South Africa, Legodi et al. [29], were used for the production of cellulases in solid-state fermentation. Three grams of untreated BPS was moistened to $75 \%$ with a synthetic medium, as described by Peixoto [30], in $250 \mathrm{ml}$ Erlenmeyer flasks. The synthetic medium consisted of $2 \mathrm{~g} / \mathrm{L} \mathrm{K}_{2} \mathrm{HPO}_{4}, 0.5 \mathrm{~g} / \mathrm{L} \mathrm{KCl}, 0.01 \mathrm{~g} / \mathrm{L}$ $\mathrm{FeSO}_{4} \cdot 7 \mathrm{H}_{2} \mathrm{O}, 0.15 \mathrm{~g} / \mathrm{L} \mathrm{MgSO}{ }_{4} \cdot 7 \mathrm{H}_{2} \mathrm{O}, 7 \mathrm{~g} / \mathrm{L} \mathrm{g} \mathrm{KH}{ }_{2} \mathrm{PO}_{4}, 1 \mathrm{~g} / \mathrm{L}$ $\left(\mathrm{NH}_{4}\right) \mathrm{SO}_{4}$, and $1.2 \mathrm{~g} / \mathrm{L}$ yeast extract. $\mathrm{pH}$ of the medium was adjusted to 6.5 using $1 \mathrm{M} \mathrm{NaOH}$ or $1 \mathrm{M} \mathrm{HCl}$ prior to sterilization at $121^{\circ} \mathrm{C}$ and 15 psi for $15 \mathrm{~min}$ (HL-340 Vertical Type Steam Sterilizer, Taiwan). A $1 \mathrm{~mL}$ spore suspension $\left(1 \times 10^{8}\right.$ spores $\left./ \mathrm{ml}\right)$ of either $T$. longibrachiatum LMLSAUL 14-1 or T. harzianum LMLBP07 13-5 was inoculated into separate $250 \mathrm{ml}$ Erlenmeyer flasks (in triplicate) each containing $3 \mathrm{~g}$ of untreated BPS. The flasks were incubated at $30^{\circ} \mathrm{C}$ for 9 days without shaking (Incubator Shaker Series, New Brunswick, Excella E25R). The whole content of a flask was sampled from day 3 up to day 9.

Enzyme extraction was carried out by the modified method described by El-Shishtawy et al. [31]. Crude enzyme was extracted by adding $50 \mathrm{~mL}$ of $0.05 \mathrm{M}$ sodium citrate buffer ( $\mathrm{pH} 4.8$ ) to the fermented contents in the flasks with intermittent shaking for 1 hour at room temperature $\left(20-25^{\circ} \mathrm{C}\right)$. The mixture was filtered and centrifuged at $3834 \times \mathrm{g}$ for $10 \mathrm{~min}$ (Beckman Coulter Allegra X-22R refrigerated benchtop centrifuge), and the supernatant was used for enzyme assays. Filter paper activity was used to determine total cellulase activity of the crude enzyme using the following equation:

$$
\operatorname{FPA}\left(\frac{\mathrm{FPU}}{\mathrm{mL}}\right)=\frac{0.37}{[\mathrm{Enz}]}
$$

where FPU is the filter paperase activity unit and [Enz] is the concentration of the enzyme that releases $2.0 \mathrm{mg}$ of glucose from the $50 \mathrm{mg}$ filter paper in 60 minutes under the conditions of the assay [32]. For cellulase activity in SSF, FPU/ $\mathrm{mL}$ was converted into FPU/g d.s (d.s refers to dry substrate) using the following equation [33]:

$$
\begin{aligned}
\text { FPA } & \left(\frac{\text { FPU }}{\mathrm{gd} . \mathrm{s}}\right) \\
= & \frac{(\mathrm{FPU} / \mathrm{mL}) \times \text { total volume of the fungal extract }(\mathrm{mL})}{\text { dry weight of the substrate used in SSF }(\mathrm{g})} .
\end{aligned}
$$

2.6. Enzymatic Hydrolysis of the Pretreated Banana Pseudostem. Crude cellulases from T. longibrachiatum LMLSAUL 14-1 and T. harzianum LMLBP07 13-5 cultures were used for enzymatic hydrolysis. The hydrolysis of alkaline $(3 \% \mathrm{NaOH})$, acid $\left(5 \% \mathrm{H}_{2} \mathrm{SO}_{4}\right)$, and $\mathrm{LHW}$ pretreated BPS at $10 \mathrm{~g}, 12.5 \mathrm{~g}$, and $15 \mathrm{~g}$ (i.e., 10, 12.5, and 15\%) solid loadings in $100 \mathrm{~mL} 0.05 \mathrm{M}$ sodium citrate ( $\mathrm{pH} 5.0$ ) was carried out in triplicate at $50^{\circ} \mathrm{C}$ and $150 \mathrm{rpm}$ for 76 hours. The hydrolysis reaction mixture contained crude enzyme (10 FPU/g of the substrate equivalent to total protein concentration of $29.3 \mathrm{mg} / \mathrm{g}$ substrate, Yang et al. [34] and Gregg and Saddler [35]) and $0.005 \%$ sodium azide. Sampling was 
carried out according to Low et al. [36]. Sugar analysis was performed according to the procedure followed under the pretreatment section.

2.7. Sugar Analysis in Banana Pseudostem Hydrolysate. The sugars in the BPS hydrolysate samples were analysed using HPLC on a Shimadzu Prominence 20 HPLC system (Shimadzu, Kyoto, Japan) equipped with a Rezex RHMmonosaccharide $\mathrm{H}+$ column $(300 \times 7.8 \mathrm{~mm})$ fitted with a 5 micron Rezex organic guard column (Phenomenex, USA). Detection of eluents was done by using a refractive index detector, RID 10A (Shimadzu, Kyoto, Japan). The column temperature was maintained at $85^{\circ} \mathrm{C}$, and analytes were eluted using deionised water at a flow rate of $0.6 \mathrm{ml} / \mathrm{minute}$. Peak detection and integration were done using LC Solution software from Shimadzu (Kyoto, Japan), and peak heights were used for calculations of sugar concentrations. Known concentrations of glucose, xylose, and cellobiose were used as standards to determine the concentration of individual sugars in BPS hydrolysates.

The calculation of the glucose yield or saccharification yield as a percentage of cellulose converted into glucose (\% digestibility) during enzymatic hydrolysis was done according to the method by Matsakas et al. [27].

$$
\eta=100 *\left(\frac{C_{\text {glucose }} * V_{\text {liquid }} * 0.90}{m_{\text {solids }} * x_{\text {cellulose }}}\right) \text {, }
$$

where $C_{\text {glucose }}$ is the glucose concentration minus any glucose present at the beginning of hydrolysis $(\mathrm{g} / \mathrm{L})$ as determined by HPLC, $V_{\text {liquid }}$ is the volume of liquid $(L)$ used in saccharification, 0.90 is the correction factor for the conversion of cellulose to glucose, $x_{\text {cellulose }}$ is the mass fraction of cellulose (expressed in dry biomass, $\mathrm{g} / \mathrm{g}$ ), and $m_{\text {solids }}$ is the mass of dry solids $(\mathrm{g} / \mathrm{L})$.

\subsection{Selected Saccharification Condition and Cultivation of} Yeast. The fermentation medium used was hydrolysate from $15 \%$ loading of alkaline pretreated BPS hydrolysed with an increased dosage of crude cellulases $(66.7 \mathrm{mg}$ protein/g d.s equivalent to $20 \mathrm{FPU} / \mathrm{g}$ d.s) from $T$. longibrachiatum LMLSAUL 14-1 to achieve high sugar concentration. After $48 \mathrm{~h}$ of saccharification, hydrolysate of alkaline pretreated BPS was obtained by centrifuging the slurry at $3834 \times \mathrm{g}$ with temperature maintained at $4^{\circ} \mathrm{C}$ for 30 minutes (Beckman Coulter Allegra $\mathrm{X}-22 \mathrm{R}$ refrigerated benchtop centrifuge). The glucose content of the hydrolysate was determined to be $74 \mathrm{~g} / \mathrm{L}$ using HPLC. Bioethanol was produced through separate hydrolysis and fermentation (SHF). For inoculum preparation, Saccharomyces cerevisiae UL01 isolated from fermented sorghum was inoculated into $50 \mathrm{ml}$ of the YPD (1\% yeast extract, $2 \%$ peptone, and $2 \%$ dextrose) medium contained in $100 \mathrm{~mL}$ Erlenmeyer flasks and incubated at $30^{\circ} \mathrm{C}$ with shaking at $150 \mathrm{rpm}$ for 14 hours (Incubator Shaker Series, New Brunswick, Excella E25R).

2.8.1. Separate Hydrolysis and Fermentation. A $100 \mathrm{~mL}$ fraction of the fermentable sugars obtained from both acid pretreated BPS prehydrolysate and enzymatic alkaline pretreated BPS hydrolysate in $250 \mathrm{~mL}$ Erlenmeyer flasks was supplemented with $0.2 \mathrm{~g} \mathrm{~K}_{2} \mathrm{HPO}_{4}, 0.7 \mathrm{~g} \mathrm{KH}_{2} \mathrm{PO}_{4}, 0.1 \mathrm{~g}$ $\mathrm{NH}_{4} \mathrm{SO}_{4}$, and $0.15 \mathrm{~g}$ yeast extract following a modification of the procedure given by Thakur et al. [37]. $\mathrm{pH}$ of the BPS hydrolysate medium was adjusted to 5.0, and it was autoclaved at $121^{\circ} \mathrm{C}$ and 15 psi for 15 minutes (HL-340 Vertical Type Steam Sterilizer, Taiwan) prior to inoculation. The BPS hydrolysate medium was allowed to cool and thereafter inoculated with $S$. cerevisiae UL01 to initial $\mathrm{OD}_{600 \mathrm{~nm}}$ of 0.4 $\left(t_{0}\right)$ and incubated at $30^{\circ} \mathrm{C}$ and $100 \mathrm{rpm}$ for 48 hours. The progress of fermentation was monitored through periodic sampling, and the samples were filtered through nonsterile $0.22 \mu \mathrm{m}$ syringe filter membranes prior to glucose and ethanol analysis.

\subsubsection{Ethanol Analysis in Fermented Hydrolysate.} Ethanol was analysed by capillary gas chromatography using Shimadzu GC-2010 Plus equipped with autoinjector AOC 20i (Shimadzu) and an AOC 20S (Shimadzu) autosampler with a flame ionization detector (FID) and Zebron ZBWAXplus $30 \mathrm{M}$ (Phenomenex, USA) column $(30 \mathrm{~m}$, $0.25 \mathrm{~mm}$ ID and film thickness of $0.25 \mu \mathrm{m})$. Nitrogen was used as the carrier gas at a flow rate of $17.6 \mathrm{~mL} / \mathrm{minute}$. The oven temperature was initially maintained at $40^{\circ} \mathrm{C}$ for 1 minute, then increased to $140^{\circ} \mathrm{C}$ at a rate of $20^{\circ} \mathrm{C} / \mathrm{min}$, and further increased to $200^{\circ} \mathrm{C}$ at a rate of $50^{\circ} \mathrm{C} / \mathrm{min}$ and maintained at this temperature for 3 minutes. The injection temperature was $200^{\circ} \mathrm{C}$, and the injection volume was $1 \mu \mathrm{L}$. A split injection mode with a split ratio of 10 was applied. Ethanol was detected using a FID at $250^{\circ} \mathrm{C}$. Absolute ethanol was used for the preparation of standard concentrations ( $\mathrm{v} /$ v). Peaks' detection and integration were done using GC Solution software from Shimadzu (Kyoto, Japan). Peak heights were used to determine the unknown concentrations of ethanol in fermented BPS hydrolysate.

The conversion of cellulose to ethanol (\%) was calculated based on the weight of biomass using the method given by Lu et al. [38]:

$$
\text { ethanol yield }(\%)=\frac{[\mathrm{EtOH}]}{(f * \text { biomass } * 1.111 * 0.51)} \times 100 \text {, }
$$

where $[\mathrm{EtOH}]$ is ethanol at the end of the fermentation minus any ethanol available in the medium $(\mathrm{g} / \mathrm{L})$ at time $0 ; f$ is the cellulose fraction of dry BPS biomass $(\mathrm{g} / \mathrm{g})$; biomass is the dry biomass concentration at the beginning of the fermentation $(\mathrm{g} / \mathrm{L}) ; 0.51$ is the conversion factor for glucose to ethanol based on stoichiometric biochemistry of yeast; and 1.111 is the conversion factor of cellulose to equivalent glucose.

2.9. Statistical Analysis. All experiments were performed in triplicate. The data generated were statistically analysed by a two-way analysis of variance (ANOVA) test for saccharification experiments using MS Excel 2010. Differences were considered significant when probability value $p$ was $<0.05$. Error bars in the graphs represent standard deviation (SD). 


\section{Results}

3.1. Pretreatment and Chemical Compositional Changes of the Banana Pseudostem. Banana pseudostem is a clustered cylindrical aggregation of leaf stalk bases. BPS contains polymers, such as cellulose, hemicellulose, and lignin [39]. The ultimate goal for applying different pretreatments of BPS was to determine and select the pretreatment that modifies the structural and chemical characteristics of the biomass to enhance its susceptibility to enzymatic hydrolysis. Pretreatment introduced changes in the structure of the BPS and opened the structure to expose the carbohydrate polymers by allowing improved enzyme access to the biomass, which leads to improved enzymatic hydrolysis (saccharification). The amounts of the three polymers found in the untreated and pretreated BPS are shown in Table 1. The pretreatment results showed an increase in the percentage of cellulose (Table 1) and a loss of hemicellulose as well as lignin (Tables 1 and 2). The loss of lignin is desirable since it has been shown that lignin binds and limits the accessibility of cellulases to cellulose [40].

Table 2 shows the effect of different pretreatments on the solubilisation of the BPS and the amount of sugars (i.e., glucose) been released in the process.

Both thermo-alkaline and thermo-acid pretreatments solubilised $60 \%$ of hemicellulose present and removed about $50 \%$ of lignin (Table 2). Alkaline and acid pretreatments improved cellulose availability by $114 \%$ and $97 \%$, respectively. Hot water pretreatment of the BPS resulted in $41 \%$ hemicellulose solubilisation, $42 \%$ lignin removal, and very little change in the cellulose content.

3.2. Characterization of the Untreated and Pretreated BPS. FTIR spectroscopy was used to study the chemical, structural, and conformational variations introduced by the pretreatment of BPS. Lignocellulosic biomass contains many $\mathrm{O}-\mathrm{H}$ bonds due to the presence of cellulose, hemicellulose, and lignin. During FTIR analysis, the covalent bonds of the functional groups absorb a certain amount of energy from infrared radiation, causing the bonds to stretch. The stretching of the bonds leads to an increase in peak intensity indicated by either sharpness or broadness [41].

The FTIR spectra of the native (untreated) and pretreated BPS are shown in Figure 2. The spectrum of the native BPS shows distinct peaks/bands at various wavenumbers with strong broad bands occurring at $3363 \mathrm{~cm}^{-1}$, $2931 \mathrm{~cm}^{-1}, 2794 \mathrm{~cm}^{-1}, 1619 \mathrm{~cm}^{-1}, 1263 \mathrm{~cm}^{-1}$, and $1010 \mathrm{~cm}^{-1}$ and multiple small peaks at $863 \mathrm{~cm}^{-1}, 759 \mathrm{~cm}^{-1}, 725 \mathrm{~cm}^{-1}$, and $718 \mathrm{~cm}^{-1}$. The spectra of all pretreated BPS fibres are similar to those of the native BPS and exhibit common peaks and values, which indicate the similarity between samples. However, chemical modification through pretreatment has decreased the peaks' intensities, and some peaks completely disappeared. For instance, the peak at wavenumber $2794 \mathrm{~cm}^{-1}$ disappeared in all the pretreated BPS samples, suggesting solubilisation of hemicellulose (Table 2). There was a decrease in peak intensities of the pretreated BPS samples at wavenumbers $3363 \mathrm{~cm}^{-1}, 2931 \mathrm{~cm}^{-1}, 1619 \mathrm{~cm}^{-1}$,
TABLE 1: Chemical composition of the untreated and pretreated banana pseudostem.

\begin{tabular}{lccc}
\hline $\begin{array}{l}\text { BPS and } \\
\text { pretreatment }\end{array}$ & $\begin{array}{c}\text { Cellulose } \\
(\%)\end{array}$ & $\begin{array}{c}\text { Hemicellulose } \\
(\%)\end{array}$ & Lignin (\%) \\
\hline Untreated & $24.47 \pm 0.84$ & $22.56 \pm 1.66$ & $14.14 \pm 1.59$ \\
$3 \% \mathrm{NaOH}$ & $52.32 \pm 2.88$ & $10.84 \pm 1.59$ & $8.68 \pm 0.46$ \\
$5 \% \mathrm{H}_{2} \mathrm{SO}_{4}$ & $48.17 \pm 0.35$ & $9.88 \pm 1.64$ & $8.31 \pm 1.69$ \\
Hot water & $25.44 \pm 0.31$ & $15.02 \pm 1.19$ & $9.25 \pm 0.07$ \\
\hline
\end{tabular}

NB: standard deviation $(\mathrm{SD}) \pm$ values of three independent repeats.

$1235 \mathrm{~cm}^{-1}$, and $1010 \mathrm{~cm}^{-1}$ indicating fewer functional groups such as $\mathrm{O}-\mathrm{H}, \mathrm{C}-\mathrm{H}$, and $\mathrm{C}=\mathrm{C}$ that are associated with stretching vibrations mainly in cellulose and hemicellulose or lignin.

3.3. Hydrolysis of the Banana Pseudostem. High solid loading of BPS during enzymatic hydrolysis was selected to evaluate the efficiency of the crude cellulases from the Trichoderma species at moderate dosage and to establish the "high-solid effect" defined as a decrease in cellulose conversion yield or efficiency as solid loading increases [42]. All the pretreated BPS were exposed to enzyme digestibility assessment (saccharification) using crude cellulases from $T$. harzianum LMLBP07 13-5 and T. longibrachiatum LMLSAUL 14-1 at a concentration of $10 \mathrm{FPU} / \mathrm{g}$ d.s (equivalent to $29.3 \mathrm{mg}$ protein/g d.s).

Acid pretreated BPS exhibited recalcitrance towards the enzymatic hydrolysis by cellulases from $T$. harzianum LMLBP07 13-5. When compared with the LHW and alkaline pretreatment of BPS, there was poor release of glucose at all solid/substrate loadings. The concentration of glucose ranged from 3.8 to $5.4 \mathrm{~g} / \mathrm{L}$ with higher concentration attained at $15 \%$ substrate loading (Figure 3(a)). When the LHW pretreated BPS was exposed to enzymatic hydrolysis, released glucose ranged from 14.2 to $22 \mathrm{~g} / \mathrm{L}$ after $76 \mathrm{~h}$ (Figure 3(b)). The hydrolysis rate for the LHW pretreated BPS was faster than for both chemically pretreated BPS. At $20 \mathrm{~h}$, the amount of glucose released from $12.5 \%$ substrate loading was $16 \mathrm{~g} / \mathrm{L}$ higher than the alkaline pretreated BPS with the same substrate loading. The rate of hydrolysis slowed as substrate loading increased to $15 \%$. The hydrolysis of the alkaline pretreated BPS released glucose in the range of 13.9 to $20.1 \mathrm{~g} / \mathrm{L}$ (Figure 3(c)). In all treatments, the highest concentration of glucose was attained at $15 \%$ solid loading of BPS. The concentration of glucose increased proportionally with an increase in substrate loading. At $76 \mathrm{~h}$, the hydrolysis of both LHW and alkaline pretreated BPS at all substrate loadings (10-15\%) showed no significant differences with the amount of glucose released.

The cellulose conversion to glucose of the BPS varied between the treatments. As shown in Table 3, LHW pretreated BPS had higher cellulose conversion to glucose, i.e., higher enzyme digestibility ranging from 50 to $51 \%$. Alkaline pretreated BPS was the second most digestible material with cellulose conversion between 24 and 23\%. Both LHW and alkaline pretreated BPS exhibited an increase in cellulose conversion to glucose up to a solid loading of $12.5 \%$. Further solid loading of $15 \%$ BPS decreased the conversion of 
TABLE 2: Effect of pretreatment methods on solubilisation components of the banana pseudostem.

Banana pseudostem pretreatments ( $1: 10$ of mass to liquid volume)

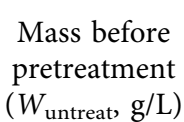

$\left(W_{\text {untreat }}, \mathrm{g} / \mathrm{L}\right)$
Percentage of solubilised components of the banana pseudostem (\%), equation (1)

\begin{tabular}{|c|c|c|c|c|c|}
\hline \multicolumn{6}{|c|}{ 11стіле } \\
\hline Alkaline & 150 & 124.5 & 17 & 60.1 & 51.0 \\
\hline Acidic & 150 & 118.5 & 21 & 65.4 & 54.0 \\
\hline Liquid hot water & 150 & 132.0 & 12 & 41.4 & 42.4 \\
\hline
\end{tabular}

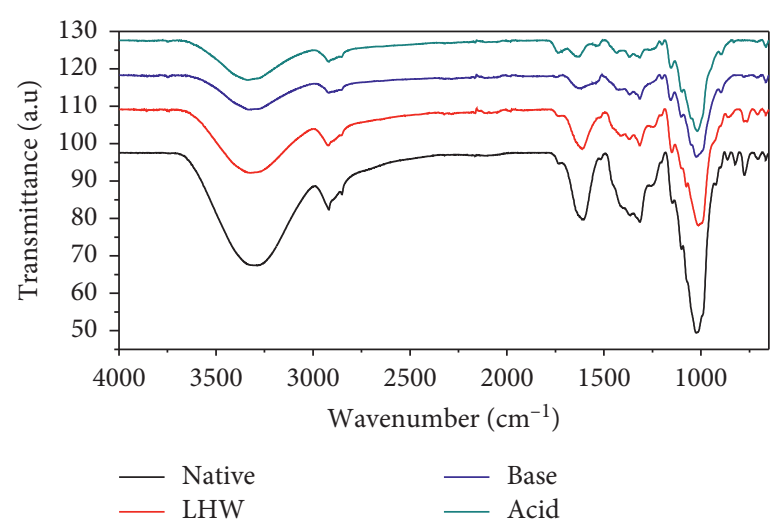

FIgURe 2: FTIR spectra of the banana pseudostem. -, native (untreated); -, LHW (liquid hot water); -, base (3\% NaOH); -, acid (5\% $\mathrm{H}_{2} \mathrm{SO}_{4}$ ).

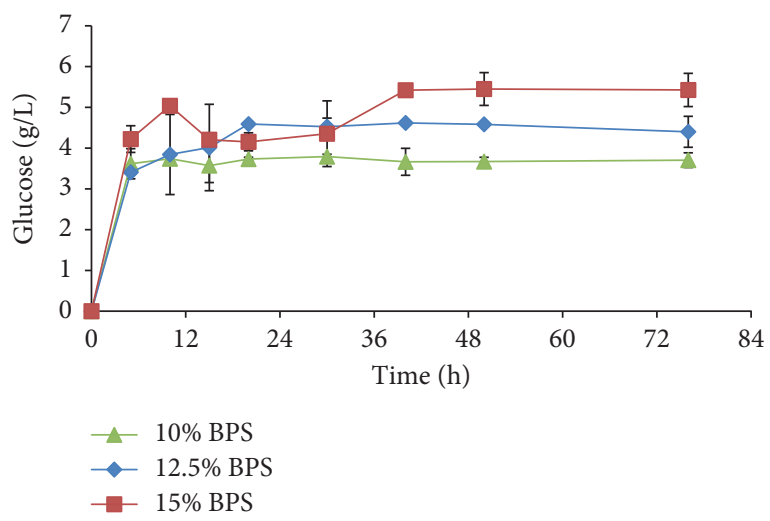

(a)

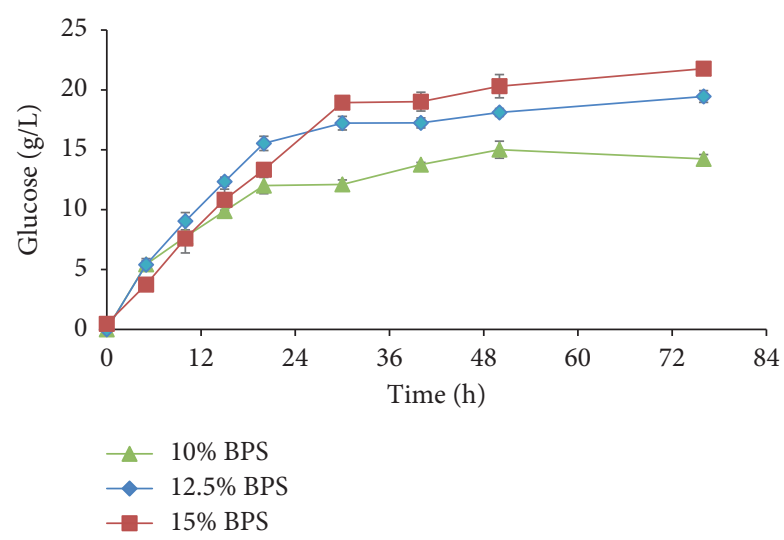

(b)

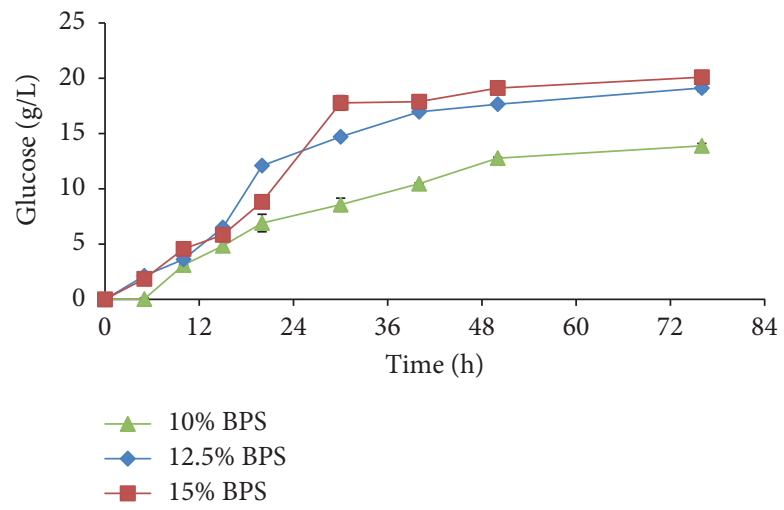

(c)

Figure 3: Time course of the pretreated BPS by the crude enzyme from T. harzianum LMLBP07 13-5: (a) acid; (b) LHW; (c) alkaline. 
cellulose to glucose. There was poor cellulose conversion to glucose in the acid pretreated BPS which exhibited digestibility of $7 \%$ in all solid loadings.

The hydrolysis of the acid pretreated BPS by cellulases from $T$. longibrachiatum LMLSAUL 14-1 is shown in Figure 4(a). Most of the sugar was released within the first 5 to 10 hours of incubation, and a further increase in hydrolysis time did not improve the glucose concentration significantly. The hydrolysis of LWH by crude cellulases from T. longibrachiatum LMLSAUL 14-1 showed a lag phase up to $10 \mathrm{~h}$, a period in which the hydrolysis rate of the enzymes slowed. After $10 \mathrm{~h}$, the hydrolysis rate increased, thereby releasing glucose that ranged from 25 to $31 \mathrm{~g} / \mathrm{L}$ at $76 \mathrm{~h}$ (Figure 4(b)). The cellulases produced by T. longibrachiatum LMLSAUL 14-1 were more effective in hydrolysing alkaline pretreated BPS (Figure 4(c)). The hydrolysis rate for the alkaline pretreated BPS was faster than the rate for the LHW pretreated BPS. The enzymatic hydrolysis released glucose in the range of 29.7 to $43.5 \mathrm{~g} / \mathrm{L}$. The amounts of glucose released from the hydrolysis of the alkaline pretreated BPS were significantly higher than the other pretreated BPS. Glucose obtained from LHW and alkaline pretreatments was directly proportional to the solid loading of the BPS.

A significant improvement in the enzymatic conversion of the LHW pretreated BPS was evident when compared with other pretreatments (Table 4). The highest glucose yields or percent of saccharification ranged from 87 to $73 \%$, which was attained by using 10 to 15\% LHW pretreated BPS solid loading that was hydrolysed by crude cellulases from T. longibrachiatum LMLSAUL 14-1. In comparison to the digestibility of the LHW BPS that remained high, there was a parallel proportional decrease in alkaline BPS conversion to glucose with increasing solid loading up to $15 \%$. Similarly, in the alkaline pretreated PBS, the glucan conversion efficiency decreased only after $12.5 \%$ solid loading (Table 4 ). Although the cellulose or glucan conversion efficiency of the alkaline pretreated PBS was lower than the LHW pretreated BPS, the hydrolysis of the alkaline pretreated BPS released more sugar than all other pretreated PBS at the end of the reaction. Acid pretreated BPS cellulose conversion to glucose remained poor in all solid loadings, and therefore, lower glucose concentration was obtained.

Based on the glucose concentration obtained from the hydrolysis reactions of the alkaline pretreated BPS with $T$. longibrachiatum LMLSAUL 14-1 cellulases, this reaction was chosen for further use in fermentation studies.

3.4. Separate Hydrolysis and Fermentation of Enzymatic Alkaline BPS Hydrolysate. Acid hydrolysis of lignocellulosic biomass has been reported to yield high concentrations of fermentable sugars, but it produces toxic substances that requires the neutralization step prior to fermentation. This adds more cost to bioethanol production [43]. As opposed to acid hydrolysis, enzymatic hydrolysis uses very mild reaction conditions and produces very little toxic compounds [44]. After hydrolysis of the alkaline pretreated BPS with $T$. longibrachiatum LMLSAUL 14-1 cellulases, the amount of glucose released reached $74 \mathrm{~g} / \mathrm{L}$. The fermented alkaline pretreated BPS enzymatic hydrolysate was shown containing $17.6 \mathrm{~g} / \mathrm{L}$ concentration of ethanol at the end of fermentation by converting $51 \%$ of available glucose, with residual glucose of $36.3 \mathrm{~g} / \mathrm{L}$ (Figure 5). The fermentation was sluggish and incomplete. The ethanol yield was $60 \%$ of the theoretical maximum.

\section{Discussion}

4.1. Chemical Composition of the Banana Pseudostem. Different BPS portions, outer sheath, middle portion, and core portion (i.e., pith), were mixed and analysed for its polymer content. The cellulose content of the untreated BPS (24.5\%, Table 1) was comparable to $20.1 \%$ reported by Guerrero et al. [45]. Several authors reported between 30 and $44 \%$ cellulose, 15 and $30 \%$ hemicellulose, and 6 and $12 \%$ lignin in the untreated BPS [13,21,37, 46-48]. The discrepancies in chemical composition may be attributed to the cultivar of the banana plant and climatic (geographic) conditions. Pretreatment of the BPS changed its chemical, physical, and morphological structure. This observation was evident as shown in by FTIR analysis (Table 1 and Figure 2). The results showed an increase in cellulose and partial loss of hemicellulose and lignin, particularly in chemically pretreated BPS compared to the hydrothermally (liquid hot water) pretreated BPS. The effect of acid and alkaline pretreatments on the reduction of hemicellulose and lignin in the BPS is consistent with the findings of de Souza et al. [48].

Available cellulose in the pretreated BPS with alkaline solution $(3 \% \mathrm{NaOH})$ reported in this study was lower as shown in Table 1 when compared to $73.74 \%$ BPS cellulose obtained when higher alkaline concentration $(4 \% \mathrm{NaOH})$ was used by Low et al. [36]. Hemicellulose at $8.35 \%$ and lignin at $10.1 \%$ are in agreement with our results. These authors also observed that prolonged soaking times and increased concentration of $\mathrm{NaOH}$ did not result in complete removal of lignin. The loss of hemicellulose in $\mathrm{NaOH}$ pretreated biomass is thought to be the result of a peeling mechanism, which removes the terminal sugar molecules one at a time from the reducing end [49]. The modification of biomass by pretreatment removes hydrogen bonding in the biomass network structure. The effects of pretreatment on the BPS chemical composition were found similar to those observed in agricultural residues. For example, pretreatment of wheat straw (WS) by hydrothermal and steam explosion increased the cellulose content and reduced the hemicellulose content [50, 51]. Zhang et al. [52] reported about $58 \%$ cellulose, $28.85 \%$ hemicellulose, and $17.75 \%$ lignin, which amounted to a $19.53 \%$ increase of cellulose and $13.98 \%$ decrease of lignin content with a small increase of hemicellulose after mild alkaline pretreatment $(1 \% \mathrm{NaOH})$ of wheat straw. The higher cellulose content and reduced hemicellulose and lignin contents enhanced enzymatic saccharification. Motaung and Anandjiwala [28] also observed an increase of cellulose with the decrease of hemicellulose and lignin contents in chemically pretreated sugarcane bagasse. In addition, the authors also mentioned higher cellulose and hemicellulose contents in 
TABLE 3: Summary of the enzymatic hydrolysis of pretreated banana pseudostems at varying solid loadings by crude enzymes produced by Trichoderma harzianum LMLBP07 13-5.

\begin{tabular}{lccccc}
\hline Pretreatment & $\begin{array}{c}\text { BPS biomass loading }(\% \\
\mathrm{w} / \mathrm{v})\end{array}$ & $\begin{array}{c}\text { Crude cellulase loading } \\
(\mathrm{FPU} / \mathrm{g} \mathrm{d} . \mathrm{s})\end{array}$ & $\begin{array}{c}\text { Glucose produced } \\
(\mathrm{g} / \mathrm{L})\end{array}$ & $\begin{array}{c}\text { Time } \\
(\mathrm{h})\end{array}$ & $\begin{array}{c}\text { Cellulose conversion to glucose } \\
(\% \mathrm{w} / \mathrm{w}), \text { equation }(4)\end{array}$ \\
\hline \multirow{2}{*}{$5 \%(\mathrm{v} / \mathrm{v}) \mathrm{H}_{2} \mathrm{SO}_{4}$} & 10 & 10 & $3.8( \pm 0.06)$ & 30 & $7.1( \pm 0.11)$ \\
& 12.5 & 10 & $4.6( \pm 0.02)$ & 40 & $6.9( \pm 0.03$ \\
\hline \multirow{2}{*}{$\mathrm{LHW}$} & 15 & 10 & $5.4( \pm 0.40)$ & 40 & $6.8( \pm 0.50)$ \\
& 10 & 10 & $14.2( \pm 0.36)$ & 76 & $50.2( \pm 0.59)$ \\
\hline \multirow{2}{*}{$3 \%(\mathrm{w} / \mathrm{v})$} & 12.5 & 10 & $19.5( \pm 0.49)$ & 76 & $55.2( \pm 0.71)$ \\
$\mathrm{NaOH}$ & 15 & 10 & $21.8( \pm 0.50)$ & 76 & $51.4( \pm 0.79)$ \\
\hline
\end{tabular}

Standard deviation \pm values of three independent repeats.

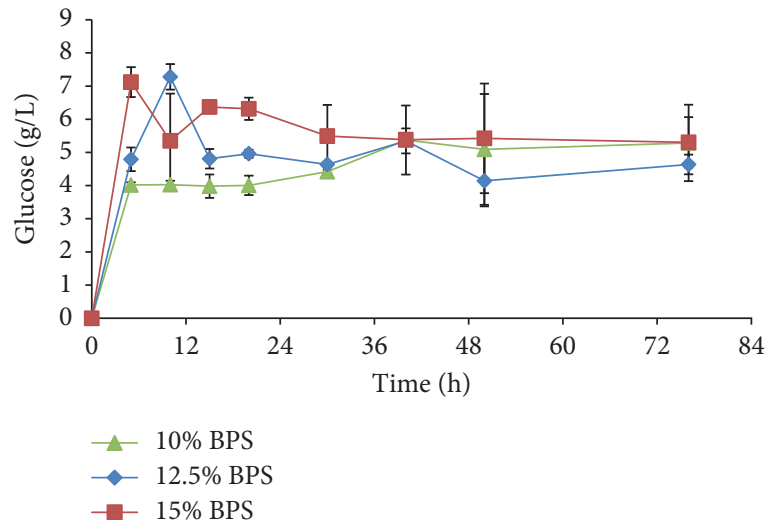

(a)

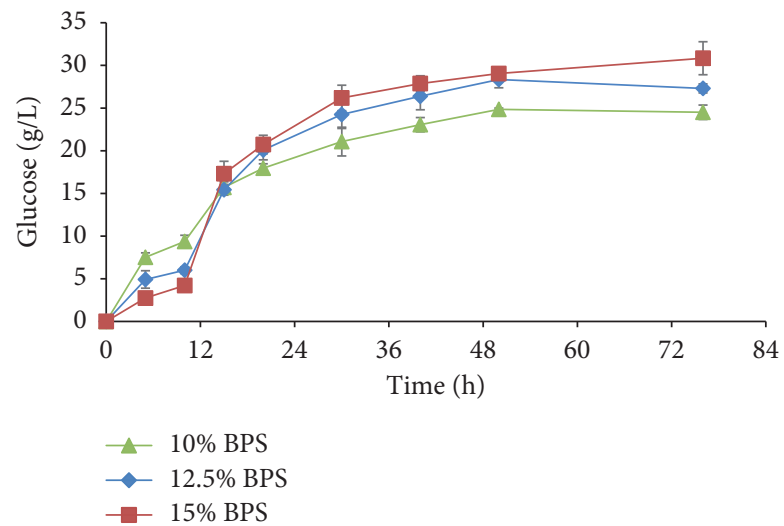

(b)

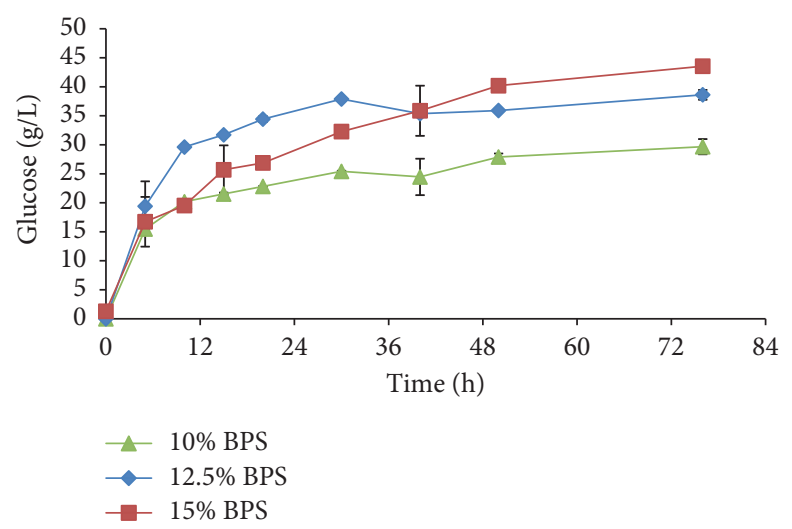

(c)

FIGURE 4: Time course of the pretreated BPS by the crude enzyme from T. longibrachiatum LMLSAUL 14-1: (a) acid; (b) LHW; (c) alkaline.

acid pretreated sugarcane bagasse $(\mathrm{SB})$ than in alkaline pretreated SB.

\subsection{Characterization of the Untreated and Pretreated Banana} Pseudostem. FTIR spectroscopy was used to analyse the chemical, structural, and conformational variations introduced by pretreatment in the BPS. The broad band (peak) occurring at wavenumber $3363 \mathrm{~cm}^{-1}$ in Figure 2 was associated with the intermolecular $\mathrm{O}-\mathrm{H}$ stretching vibrations of cellulose and $2931 \mathrm{~cm}^{-1}$ with C-H stretching absorption/ vibration from $-\mathrm{CH}_{2}$ groups of cellulose and hemicellulose [53-55]. A peak at $1619 \mathrm{~cm}^{-1}$ is associated with $\mathrm{C}=\mathrm{C}$ stretching of benzene rings in lignin and $1010 \mathrm{~cm}^{-1}$ with C-O-C stretching absorption between raw banana fibres [53]. According to Faix et al. [56], lignin compounds are characterized by the frequencies of guaiacyl units, corresponding to wavenumber $1269 \mathrm{~cm}^{-1}$ and $\mathrm{G}$-ring and $\mathrm{C}=\mathrm{O}$ stretched at $1140 \mathrm{~cm}^{-1}$. Both untreated and LHW pretreated BPS showed smaller peaks at $863 \mathrm{~cm}^{-1}$ and $759 \mathrm{~cm}^{-1}$. The 
TABLE 4: Summary of enzymatic saccharification of pretreated banana pseudostems at varying solid loadings by crude enzymes produced by Trichoderma longibrachiatum LMLSAUL 14-1.

\begin{tabular}{|c|c|c|c|c|c|}
\hline Pretreatment & $\begin{array}{l}\text { BPS biomass loading (\% } \\
\mathrm{w} / \mathrm{v})\end{array}$ & $\begin{array}{l}\text { Crude cellulase loading } \\
\text { (FPU/g d.s) }\end{array}$ & $\begin{array}{c}\text { Glucose produced } \\
(\mathrm{g} / \mathrm{L})\end{array}$ & $\begin{array}{l}\text { Time } \\
(\mathrm{h})\end{array}$ & $\begin{array}{c}\text { Cellulose conversion to glucose } \\
(\% \mathrm{w} / \mathrm{w}) \text {, equation }(4)\end{array}$ \\
\hline \multirow{3}{*}{$5 \%(\mathrm{v} / \mathrm{v}) \mathrm{H}_{2} \mathrm{SO}_{4}$} & 10.0 & 10 & $5.4( \pm 1.04)$ & 40 & $10.1( \pm 1.95)$ \\
\hline & 12.5 & 10 & $7.4( \pm 0.36)$ & 10 & $11.1( \pm 0.57)$ \\
\hline & 15.0 & 10 & $7.1( \pm 0.45)$ & 5 & $8.9( \pm 0.56)$ \\
\hline \multirow{3}{*}{ LHW } & 10.0 & 10 & $24.5( \pm 0.84)$ & 76 & $86.7( \pm 1.25)$ \\
\hline & 12.5 & 10 & $27.3( \pm 0.53)$ & 76 & $77.3( \pm 0.86)$ \\
\hline & 15.0 & 10 & $30.8( \pm 1.93)$ & 76 & $72.6( \pm 1.83)$ \\
\hline \multirow{3}{*}{$\begin{array}{l}3 \%(\mathrm{w} / \mathrm{v}) \\
\mathrm{NaOH}\end{array}$} & 10.0 & 10 & $29.7( \pm 1.31)$ & 76 & $51.1( \pm 2.26)$ \\
\hline & 12.5 & 10 & $38.6( \pm 0.85)$ & 76 & $53.1( \pm 1.17)$ \\
\hline & 15.0 & 10 & $43.5( \pm 0.70)$ & 76 & $50.0( \pm 0.81)$ \\
\hline
\end{tabular}

Standard deviation \pm values of three independent repeats.

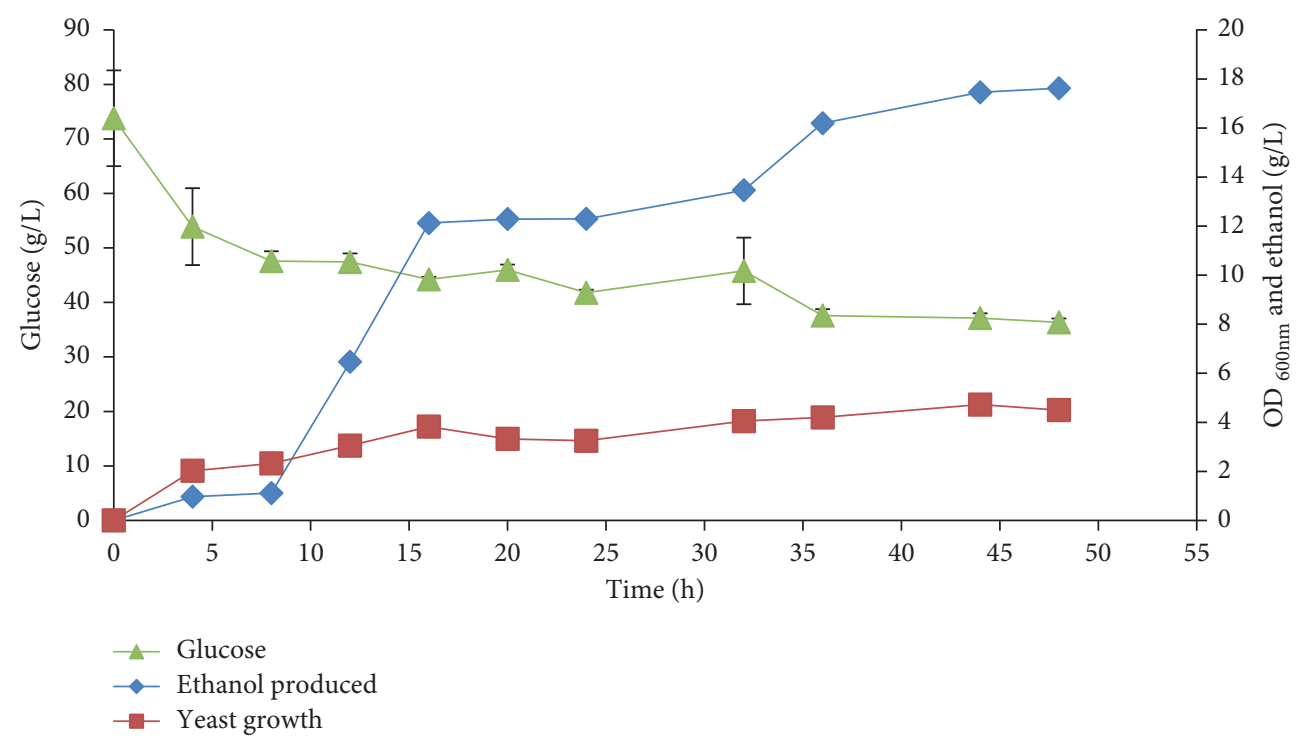

FIgURE 5: Time course of the separate hydrolysis and fermentation of the alkaline pretreated BPS saccharified with T. longibrachiatum LMLSAUL 14-1 cellulases.

peak between $800 \mathrm{~cm}^{-1}$ and $880 \mathrm{~cm}^{-1}$ is associated with $\mathrm{CH}$ in-plane deformation [57], while the peak at wavenumber $750 \mathrm{~cm}^{-1}$ signifies ArC-H out-of-plane deformation of lignin. The peaks at wavenumbers $687-625 \mathrm{~cm}^{-1}$ are associated with the out-of-plane bending vibrations of intermolecular $\mathrm{H}$-bonded $\mathrm{O}-\mathrm{H}$ groups and out-of-plane $\mathrm{O}-\mathrm{H}$ bending [58].

In another study, FTIR analysis also revealed that dilute acid pretreatment of wheat straw alone was not sufficient for complete lignin removal, although complete removal of soluble lignin was attained as shown by a slight appearance or disappearance of a peak associated with both lignin types [59]. Barreto et al. [60] found that the vibration modes of functional groups of the pretreated banana fibre did not show differences compared with the main bands of the untreated banana fibre after alkaline treatment at concentrations ranging from 0.25 to $1 \% \mathrm{NaOH}$ at $60-70^{\circ} \mathrm{C}$ for 6 hours. However, there were clear differences between the pretreated and untreated BPS biomass. The difference between the observation reported by Barreto et al. [60] and the finding in this study could be attributed to pretreatment conditions as the current study used a higher percentage of $\mathrm{NaOH}(3 \% \mathrm{w} / \mathrm{v})$ and temperature $\left(121^{\circ} \mathrm{C}\right)$ to BPS.

4.3. Hydrolysis of the Banana Pseudostem. The sole purpose of hydrolysis is to release sugars, mainly glucose (and xylose depending on the enzyme composition), which will be fermented in the subsequent steps. Enzymatic hydrolysis (saccharification) of lignocellulosic biomass is dependent on both the availability of cellulose or hemicellulose and the hydrolytic activity of the enzymes used. In this study, saccharification of BPS was carried out with an enzyme dosage of $10 \mathrm{FPU} / \mathrm{g}$ substrate (equivalent to $29.3 \mathrm{mg}$ protein $/ \mathrm{g} \mathrm{d.s}$ ). Substrate loading ranged from 10 to $15 \%$. Based on reported findings by Lu et al. [61], Sun and Cheng [62], and Gregg and Saddler [35], cellulase dosage for effective hydrolysis could vary between 7 and $33 \mathrm{FPU} / \mathrm{g}$ substrate, depending on the type of substrate. Guerrero et al. [45] achieved hydrolysis of banana waste with $15 \mathrm{FPU} / \mathrm{g}$ cellulase dosage with a high solid loading (i.e., higher than 15\% solid loading). 
During hydrolysis of the BPS, the concentration of glucose has increased proportionally with increasing solid loading of pretreated BPS biomass. However, the cellulose or glucan conversion efficiency (i.e., glucose yield) to glucose increased up to $12.5 \%$ solid loading, and the efficiency reduced with further increases of solid loadings (Tables 3 and 4). The enzymatic release of the sugars from the acid pretreated BPS was poor because of the indigestibility of cellulose fibres, which may contain many crystalline regions on the cellulose surface. This observation is in agreement with the findings by Abraham et al. [63], who showed that oxalic acid hydrolysis solubilised amorphous regions in cellulose leaving more crystalline regions in the cellulose fibres. An increase in oxalic acid concentration up to $10 \%$ increased the crystallinity of the BPS, jute stem, and pineapple leaf fibre. A concentration of oxalic acid higher than $20 \%$ degraded cellulose fibres [63]. Another possible reason may be that the enzyme concentration used for hydrolysis is not optimal for achieving high glucose at a solid loading higher than $10 \%$. For instance, Shimizu et al. [64] reported the hydrolysis of $2 \%$ solid loading (i.e., $0.1 \mathrm{~g}$ in $5 \mathrm{~mL}$ reaction volume) of acid ( $5 \% \mathrm{v} / \mathrm{v} \mathrm{H}_{2} \mathrm{SO}_{4}$ ) pretreated BPS by commercial enzymes (15 FPU/g cellulase, Celluclast $1.5 \mathrm{~L}$, Novozyme, and $15 \mathrm{U} / \mathrm{g}$ cellobiase, $\beta$-glucosidase, and Novozyme 188), which provided sufficient enzymatic activity to achieve a glucose yield of $20 \%$.

Unlike saccharification of the acid pretreated BPS, enzymatic saccharification of LHW and alkaline pretreated BPS, which contained $40 \%$ and $63.0 \%$ holocellulose, respectively, by crude cellulases from $T$. harzianum LMLSABP07 13-5 and T. longibrachiatum LMLSAUL 14-1 was shown susceptible to enzymatic hydrolysis. The concentration of glucose $(\mathrm{g} / \mathrm{L})$ released from both $\mathrm{LWH}$ and alkaline pretreated BPS showed no significant differences after the hydrolysis by the crude enzyme from T. harzianum LMLSABP07 13-5.

An exception was the hydrolysis of the LHW pretreated BPS by crude cellulases from T. longibrachiatum LMLSAUL 14-1, which showed reduction in glucan conversion efficiency at a biomass loading of more than $10 \%$ (Table 4). Moreover, the glucan conversion efficiency of the LHW pretreated BPS was found higher than the other saccharified pretreated BPS. Under optimized conditions, LHW could be a pretreatment of choice because it was environmentally friendly (i.e., less harmful to the environment), safe, and also economical compared to the chemical pretreatment. The reduction in cellulose efficiency at high solid loading was in agreement with the findings by Guerrero et al. [45], who observed that higher solid loadings led to a higher glucose content, but led to low cellulosic conversion efficiency. A recent study by Lu et al. [61] showed the extent to which a biomass can be hydrolysed at high solid loading and yet still achieve high conversion efficiency. The study found that, at high solid loading between 10 and $20 \%$ of corn stover, the glucose yield remained unchanged. However, further increase in solid loading to $30 \%$ led to significant reduction in glucose yield. The high conversion efficiency at $20 \%$ solid loading of corn stover was attributed to ball milling pretreatment, thereby reducing the crystallinity and the degree of polymerization of the polymers in corn stover [61]. The decrease in cellulosic conversion efficiency to glucose is highly undesirable as it diminishes the significant advantages of working at high solid loadings [65]. The enzyme-substrate interaction becomes ineffective due to the higher viscosity of the slurry. Ghose [66] found that high viscous slurry restricts enzyme movement and makes hydrolysis sites inaccessible.

Souza et al. [48] reported high crystallinity of the alkaline pretreated BPS when compared to the acid pretreated BPS, which led to poor enzymatic conversion of alkaline pretreated BPS cellulose to glucose. As a result, high reducing sugar concentrations $(33.74 \mathrm{~g} / \mathrm{L})$ were obtained from the acid pretreated BPS compared to $19.4 \mathrm{~g} / \mathrm{L}$ obtained from the alkaline pretreated BPS in the Souza et al.'s study [48]. The high digestibility of the acid pretreated BPS reported by Souza et al. [20,48] could be due to the low acid concentration (i.e., $2 \% \mathrm{H}_{2} \mathrm{SO}_{4}$ ) used as compared to $5 \% \mathrm{H}_{2} \mathrm{SO}_{4}$ used in this study. As concentration of acid increases, the severity of the pretreatment also increases; this may cause solubilisation of hemicelluloses and more amorphous regions within cellulose, making it indigestible.

According to El-Zawawy et al. [24], the concentration of glucose in the hydrolysate was influenced by the type of pretreatment used and the type of hydrolysis. The authors utilised the steam explosion pretreatment of banana plant waste followed by the enzymatic hydrolysis of the plant waste by cellulases from $T$. reesei ATCC 26921, which released a higher concentration of glucose. Filho et al. [23] found that the alkaline pretreated BPS was susceptible to enzyme hydrolysis, which resulted in a 23-fold increase of fermentable sugars as compared to an 8-fold increase obtained through acid hydrolysis. Another study on the BPS, Thakur et al. [37], also found that alkaline $(4 \% \mathrm{NaOH}$, slightly higher than the concentration used in the current study) pretreatment of BPS and WS yielded higher concentrations of reducing sugars compared to acid $\left(5 \% \mathrm{H}_{2} \mathrm{SO}_{4}\right)$ and biological (fungal) pretreatments. Chidi et al. [67] also found that the alkaline $(2 \% \mathrm{NaOH})$ pretreatment of BPS combined with microwave irradiation ( $170 \mathrm{~W}, 10$ minutes) yielded the highest concentration of reducing sugar for the production of bioethanol.

Alrumman [68] investigated the effect of substrate loading of palm leaves at concentration $1-8 \%$ and found that a $4 \%$ substrate loading of alkaline pretreated date palm leaves produced the highest sugar concentration during saccharification. Xu et al. [69] inferred that alkaline pretreatment technology is a promising pretreatment method of lignocellulosic biomass resulting in relatively low lignin, leading to improved enzymatic digestibility. Technoeconomic and environmental studies conducted by Duque et al. [4] listed banana pseudostem amongst other agricultural residues, such as sugarcane bagasse, corn cob, and rice husk, as a potential feedstock for the production of bioethanol. It was reported that future work should focus on developing efficient enzyme cocktail formulations to hydrolyse different types of lignocellulosic biomass to make cellulosic ethanol a cost-effective process [45]. It is imperative to select a suitable pretreatment method that maximises the concentration of fermentable sugar after 
enzymatic saccharification in order to improve the efficiency of cellulosic bioethanol production [70]. Given the amount of polymers in the BPS, particularly cellulose and hemicellulose (Table 1) and solubilised sugars (Table 2), which are present in the liquid fraction after the pretreatment, necessitates further studies that combine sugars in the liquors and sugars from solid fraction for fermentation in order to achieve higher ethanol yields and make the process cost effective.

4.4. Production of Ethanol through Separate Hydrolysis and Fermentation. During saccharification, $74 \mathrm{~g} / \mathrm{L}$ of glucose was produced in enzymatic alkaline BPS hydrolysate. The glucose levels reported in this study were higher than the levels obtained from $5 \mathrm{~g}$ pretreated banana pseudostem (15.3 g/L sugar) reported by Thakur et al. [37]. The production of ethanol is strongly dependent on the growth of the fermenting organism. Saccharomyces cerevisiae is known to consume glucose rapidly during growth and tolerate high levels of ethanol. However, poor growth of S. cerevisiae UL01 in the early stages of fermentation in enzyme hydrolysate (after alkaline pretreatment) led to high levels of residual sugar at the end of fermentation. It is desirable for a fast fermentation process of ethanol production since it results in improved ethanol productivity, which has a direct impact on the economics of the fermentation process and its commercial feasibility [71].

The sluggish and incomplete fermentation of alkaline pretreated BPS enzymatic hydrolysate yielded $18 \mathrm{~g} / \mathrm{L}$ ethanol with a $60 \%$ conversion of cellulose to ethanol and productivity of $0.01 \mathrm{~g} / \mathrm{L} / \mathrm{h}$. The incomplete fermentation could be attributed to residual inhibitory substances such as inorganic salts and phenolics that adsorbed onto the polymer fibres after the BPS solid washing step (i.e., ineffective washing) since no detoxification process was done. Thakur et al. [37] also produced ethanol from enzymatic hydrolysates of different pretreated BPS by S. cerevisiae NCIM 3570 . The authors found that ethanol produced in the enzymatic hydrolysate of the alkaline pretreated BPS reached a maximum of $3.8 \mathrm{~g} / \mathrm{L}$ with an ethanol yield of $0.35 \mathrm{~g} / \mathrm{g}$, which were higher than the levels obtained from the acid pretreated BPS $(1.9 \mathrm{~g} / \mathrm{L}$ and $0.20 \mathrm{~g} / \mathrm{g})$. Although enzymatic hydrolysate of the fungal pretreated BPS yielded a low ethanol concentration $(2.0 \mathrm{~g} / \mathrm{L})$, the ethanol yield was higher $(0.40 \mathrm{~g} / \mathrm{g})$ than the chemically pretreated BPS [37]. Kusmiyati and Sukmaningtyas [72] reported $4.32 \mathrm{~g} / \mathrm{L}$ ethanol produced from the alkaline $(8 \% \mathrm{NaOH})$ pretreated BPS at a $10 \%$ solid loading in simultaneous saccharification and fermentation (SSF), while El-Zawawy et al. [24] reported low ethanol concentrations $(<3.5 \mathrm{~g} / \mathrm{L})$ from banana plant waste.

\section{Conclusions}

Alkaline pretreatment of BPS resulted in a high holocellulose content. Enzymatic hydrolysis of an alkaline pretreated BPS found releasing more glucose concentration, and this was shown to be followed by the LHW pretreated BPS, irrespective of the source of cellulases used. A LHW pretreated
BPS exhibited the highest saccharification efficiency (glucan conversion efficiency) that was followed by the alkaline pretreated BPS, irrespective of cellulases used. However, high cellulose (glucan) conversion efficiency was achieved with crude cellulases from both fungal species, when the LHW pretreated BPS was hydrolysed. Although the LHW pretreatment of BPS was shown to be a promising method that can potentially substitute the chemical methods, it requires further optimization. The utilization of the BPS for cellulase and bioethanol production has the potential to lower the cost of cellulosic ethanol. The incomplete fermentation observed here requires further optimization and the use of a more robust yeast strain with improved fermentative properties.

\section{Data Availability}

The experimental data used to support the findings of this study are available from the corresponding author upon request.

\section{Conflicts of Interest}

The authors declare that they have no conflicts of interest.

\section{Authors' Contributions}

The authors would like to pay tribute to Prof. Ignatious Ncube for his contributions. The first author (corresponding author) conceptualized the ideas and designed and planned the research work. He performed experiments and data analysis. He took a lead in the drafting of the manuscript. I Ncube also conceptualized the study, performed data analysis, and supervised the study. Both D. C. La Grange and E. L. Jansen van Rensburg provided critical feedback on the data obtained and assisted to finalise the manuscript.

\section{Acknowledgments}

The authors would also like to extend their gratitude to the National Research Foundation (NRF) and the Flemish Interuniversity Council (VLIRUOS) for the financial support towards the research.

\section{References}

[1] A. Demirbas, "Competitive liquid biofuels from biomass," Applied Energy, vol. 88, no. 1, pp. 17-28, 2011.

[2] J.-R. Cheng and M.-J. Zhu, "A novel co-culture strategy for lignocellulosic bioenergy production: a systematic review," International Journal of Modern Biology and Medicine, vol. 1, no. 3, pp. 166-193, 2012.

[3] G. P. Maitan-Alfenas, E. M. Visser, and V. M. Guimarães, "Enzymatic hydrolysis of lignocellulosic biomass: converting food waste in valuable products," Current Opinion in Food Science, vol. 1, pp. 44-49, 2015.

[4] S. H. Duque, C. A. Cardona, and J. Moncada, "Technoeconomic and environmental analysis of ethanol production from 10 agroindustrial residues in Colombia," Energy \& Fuels, vol. 29, no. 2, pp. 775-783, 2015. 
[5] D. Kumar, B. Singh, and J. Korstad, "Utilization of lignocellulosic biomass by oleaginous yeast and bacteria for production of biodiesel and renewable diesel," Renewable and Sustainable Energy Reviews, vol. 73, pp. 654-671, 2017.

[6] J. Pérez, J. Muñoz-Dorado, T. de la Rubia, and J. Martínez, "Biodegradation and biological treatments of cellulose, hemicellulose and lignin: an overview," International $\mathrm{Mi}$ crobiology, vol. 5, no. 2, pp. 53-63, 2002.

[7] M. Leisola, O. Pastinen, and D. D. Axe, "Lignin-designed randomness," Bio-Complexity, vol. 2012, no. 3, pp. 1-11, 2012.

[8] M. E. Himmel, S.-Y. Ding, D. K. Johnson et al., "Biomass recalcitrance: engineering plants and enzymes for biofuels production," Science, vol. 315, no. 5813, pp. 804-807, 2007.

[9] L. R. Lynd, C. E. Wyman, and T. U. Gerngross, "Biocommodity engineering," Biotechnology Progress, vol. 15, no. 5, pp. 777-793, 1999.

[10] I. Ferreira da Silva, L. Reis Fontinelle Souto, S. R. A. Collins, A. Elliston, J. H. de Queiroz, and K. W. Waldron, "Impact of hot water and alkaline pre-treatments in cellulosic ethanol production from banana pseudostem," BioEnergy Research, vol. 13, no. 4, pp. 1159-1170, 2020.

[11] R. Kumar, M. Tabatabaei, K. Karimi, and I. Sárvári Horváth, "Recent updates on lignocellulosic biomass derived ethanol-a review," Biofuel Research Journal, vol. 3, no. 1, pp. 347-356, 2016.

[12] B. Yang and C. E. Wyman, "Pretreatment: the key to unlocking low-cost cellulosic ethanol," Biofuels, Bioproducts and Biorefining, vol. 2, no. 1, pp. 26-40, 2008.

[13] J. Gabhane, S. P. M. Prince William, A. Gadhe, R. Rath, A. N. Vaidya, and S. Wate, "Pretreatment of banana agricultural waste for bio-ethanol production: individual and interactive effects of acid and alkali pretreatments with autoclaving, microwave heating and ultrasonication," Waste Management, vol. 34, no. 2, pp. 498-503, 2014.

[14] A. Pandey, C. R. Soccol, and D. Mitchell, "New developments in solid state fermentation: I-bioprocesses and products," Process Biochemistry, vol. 35, no. 10, pp. 1153-1169, 2000.

[15] G. Liu, J. Zhang, and J. Bao, "Cost evaluation of cellulase enzyme for industrial-scale cellulosic ethanol production based on rigorous Aspen Plus modeling," Bioprocess and Biosystems Engineering, vol. 39, no. 1, pp. 133-140, 2016.

[16] L. J. Jönsson and C. Martín, "Pretreatment of lignocellulose: formation of inhibitory by-products and strategies for minimizing their effects," Bioresource Technology, vol. 199, pp. 103-112, 2016.

[17] P. Manzanares, "The role of biorefinering research in the development of a modern bioeconomy," Acta Innovations, vol. 37, no. 37, pp. 47-56, 2020.

[18] A. K. Chaurasia, H. B. Patil, B. Krishna, V. R. Subramaniam, P. V. Sane, and A. P. Sane, "Flowering time in banana (Musa spp.), a day neutral plant, is controlled by at least three FLOWERING LOCUS T homologues," Scientific Reports, vol. 7, no. 1, p. 5935, 2017.

[19] N. Abdullah, F. Sulaiman, M. A. Miskam, and R. M. Taib, "Characterization of banana (Musa spp.) pseudostem and fruit bunch stem as a potential renewable energy source," International Journal of Biological, Biomolecular, Agricultural, Food and Biotechnology Engineering, vol. 8, no. 8, pp. 815-819, 2014.

[20] E. L. Souza, G. F. Liebi, C. Marangoni, N. Sellin, M. S. Montagnoli, and O. Souza, "Bioethanol from fresh and dried banana plant pseudostem," Chemical Engineering Transactions, vol. 38, pp. 271-276, 2014.
[21] K. Li, S. Fu, H. Zhan, Y. Zhan, and L. A. Lucia, "Analysis of the chemical composition and morphological structure of banana pseudostem,” BioResources, vol. 5, no. 2, pp. 576-585, 2010.

[22] R. K. Meena, R. Sahu, P. Shukla, and S. Thakur, "Bioethanol production from lignocellulosic banana waste using co-culture techniques," Current Trends in Biotechnology and Pharmacy, vol. 9, no. 3, pp. 259-265, 2015.

[23] L. C. G. Filho, G. A. F. Achilles, N. Sellin, C. Marangoni, and O. Souza, "Hydrolysis of banana tree pseudostem and second generation ethanol production by Saccharomyces cerevisiae," Journal of Environmental Science and Engineering, vol. A2, pp. 65-69, 2013.

[24] W. K. El-Zawawy, M. M. Ibrahim, Y. R. Abdel-Fattah, N. A. Soliman, and M. M. Mahmoud, "Acid and enzyme hydrolysis to convert pretreated lignocellulosic materials into glucose for ethanol production," Carbohydrate Polymers, vol. 84, no. 3, pp. 865-871, 2011.

[25] C.-Y. Lin, M.-T. Peng, Y.-C. Tsai et al., "Bioconversion of banana pseudostem fiber to ethanol: optimization of acid pretreatment conditions and fermentation yeast selection," Asian Journal of Agriculture and Food Sciences, vol. 3, no. 4, pp. 333-342, 2015.

[26] S. Kim, "Enhancing bioethanol productivity using alkalipretreated empty palm fruit bunch fiber hydrolysate," BioMed Research International, vol. 2018, pp. 1-8, 2018.

[27] L. Matsakas, V. Raghavendran, O. Yakimenko et al., "Ligninfirst biomass fractionation using a hybrid organosolv-steam explosion pretreatment technology improves the saccharification and fermentability of spruce biomass," Bioresource Technology, vol. 273, pp. 521-528, 2019.

[28] T. E. Motaung and R. D. Anandjiwala, "Effect of alkali and acid treatment on thermal degradation kinetics of sugar cane bagasse," Industrial Crops and Products, vol. 74, pp. 472-477, 2015.

[29] L. M. Legodi, D. La Grange, E. L. J. van Rensburg, and I. Ncube, "Isolation of cellulose degrading fungi from decaying banana pseudostem and Strelitzia alba," Enzyme Research, vol. 2019, pp. 1-10, Article ID 1390890, 2019.

[30] A. B. Peixoto, "Study of the production of enzymes and gums by wild yeasts collected in various regions of Brazil," M. S. Thesis, Faculty of Food Engineering, University of Campinas, Campinas, Brazil, 2006.

[31] R. M. El-Shishtawy, S. A. Mohamed, A. M. Asiri, A.-b. M. Gomaa, I. H. Ibrahim, and H. A. Al-Talhi, "Saccharification and hydrolytic enzyme production of alkali pretreated wheat bran by Trichoderma virens under solid state fermentation," BMC Biotechnology, vol. 15, no. 1, p. 37, 2015.

[32] T. K. Ghose, "Measurement of cellulose activities," Pure and Applied Chemistry, vol. 59, no. 2, pp. 259-268, 1987.

[33] B. Adney and J. Baker, "Measurement of cellulase activities," NREL Analytical Procedure, National Renewable Energy Laboratory, Technical Report NREL/TP-510-42628, 1996.

[34] J. Yang, J. E. Kim, J. K. Kim, S. h. Lee, J.-H. Yu, and K. H. Kim, "Evaluation of commercial cellulase preparations for the efficient hydrolysis of hydrothermally pretreated empty fruit bunches," BioResources, vol. 12, no. 4, pp. 7834-7840, 2017.

[35] D. J. Gregg and J. N. Saddler, "Factors affecting cellulose hydrolysis and the potential of enzyme recycle to enhance the efficiency of an integrated wood to ethanol process," Biotechnology and Bioengineering, vol. 51, pp. 375-383, 1996.

[36] J. C. Low, R. Halis, U. K. Md Shah et al., "Enhancing enzymatic digestibility of alkaline pretreated banana pseudostem for sugar production," BioResources, vol. 10, no. 1, pp. 1213-1223, 2015. 
[37] S. Thakur, B. Shrivastava, S. Ingale, R. C. Kuhad, and A. Gupte, "Degradation and selective ligninolysis of wheat straw and banana stem for an efficient bioethanol production using fungal and chemical pretreatment," 3 Biotech, vol. 3, no. 5, pp. 365-372, 2013.

[38] J. Lu, X. Li, J. Zhao, and Y. Qu, "Enzymatic saccharification and ethanol fermentation of reed pretreated with liquid hot water," Journal of Biomedicine and Biotechnology, vol. 2012, pp. 1-9, 2012.

[39] S. Mukhopadhyay, R. Fangueiro, Y. Arpac, and U. Senturk, "Banana fibers-variability and fracture behaviour," Journal of Engineered Fibers and Fabrics, vol. 3, no. 2, pp. 39-45, 2008.

[40] G. Sigueira, V. Arantes, J. N. Saddler, A. Ferraz, and M. F. Milagres, "Limitation of cellulose accessibility and unproductive binding of cellulases by pretreated sugarcane bagasse lignin," Biotechnology for Biofuels, vol. 10, p. 176, 2017.

[41] A. Azizan, N. S. M. Shafaei, N. S. Sidek, F. Hanafi, N. Mokti, and S. Zaharudin, "Fourier transform infrared spectroscopy interpretation on pretreated Acacia auriculiformis, Melastoma malabathricum and Leucaeana leucocephala," International Journal of Applied Engineering Research, vol. 11, no. 20, pp. 10048-10051, 2016.

[42] A. S. A. da Silva, R. P. Espinheira, R. S. S. Teixeira, M. F. de Souza, V. Ferreira-Leitão, and E. P. S. Bon, "Constraints and advances in high-solids enzymatic hydrolysis of lignocellulosic biomass: a critical review," Biotechnology for Biofuels, vol. 13, no. 1, p. 58, 2020.

[43] C. M. Dodo, S. Mamphweli, and O. Okoh, "Bioethanol production from lignocellulosic sugarcane leaves and tops," Journal of Energy in Southern Africa, vol. 28, no. 3, pp. 1-11, 2017.

[44] D. R. Keshwani and J. J. Cheng, "Switchgrass for bioethanol and other value-added applications: a review," Bioresource Technology, vol. 100, no. 4, pp. 1515-1523, 2009.

[45] A. B. Guerrero, I. Ballesteros, and M. Ballesteros, "The potential of agricultural banana waste for bioethanol production," Fuel, vol. 213, pp. 76-185, 2018.

[46] N. Cordeiro, M. N. Belgacem, I. C. Torres, and J. C. V. P. Moura, "Chemical composition and pulping of banana pseudo-stems," Industrial Crops and Products, vol. 19, no. 2, pp. 147-154, 2004.

[47] C. Li, G. Liu, I. A. Nges, L. Deng, M. Nistor, and J. Liu, "Fresh banana pseudo-stems as a tropical lignocellulosic feedstock for methane production," Energy, Sustainability and Society, vol. 6, no. 1, p. 27, 2016.

[48] E. L. de Souza, N. Sellin, C. Marangoni, and O. Souza, “The influence of different strategies for the saccharification of the banana plant pseudostem and the detoxification of concentrated broth on bioethanol production," Applied Biochemistry and Biotechnology, vol. 183, no. 3, pp. 943-965, 2017.

[49] R. Gupta, Alkaline pretreatment of biomass for ethanol production and understanding the factors influencing the cellulose hydrolysis, Ph.D Dissertation, Auburn University, Auburn, Alabama, 2008.

[50] J. B. Kristensen, J. Börjesson, M. H. Bruun, F. Tjerneld, and H. Jørgensen, "Use of surface active additives in enzymatic hydrolysis of wheat straw lignocellulose," Enzyme and $\mathrm{Mi}$ crobial Technology, vol. 40, no. 4, pp. 888-895, 2007.

[51] J. B. Kristensen, L. G. Thygesen, C. Felby, H. Jørgensen, and T. Elder, "Cell wall structural changes in wheat straw pretreated for bioethanol production," Biotechnology for Biofuels, vol. 1, no. 1, p. 5, 2008.

[52] W. Zhang, Y. Lin, Q. Zhang, X. Wang, D. Wu, and H. Kong, "Optimisation of simultaneous saccharification and fermentation of wheat straw for ethanol production," Fuel, vol. 112, pp. 331-337, 2013.

[53] H. Becker, R. F. de Matos, J. A. de Souza, D. A. Lima, F. T. C. de Souza, and E. Longhinotti, "Pseudostem banana fibers: characterisation and chromium removal," Orbital: Electronic Journal of Chemistry, vol. 5, no. 3, pp. 164-170, 2013.

[54] P. Gopinathan, K. S. Subramanian, G. Paliyath, and J. Subramanian, "Genotypic variations in characteristic of nano-fabrillated cellulose derived from banana pseudostem," BioResources, vol. 12, no. 4, pp. 6984-7001, 2017.

[55] H. Shah, B. Srinivasulu, and S. C. Shit, "Influence of banana fibre chemical modification on the mechanical and morphological properties of Woven banana fabric/unsaturated polyester resin composites," Polymers from Renewable Resources, vol. 4, no. 2, pp. 61-84, 2013.

[56] O. Faix, D. S. Argyropoulos, D. Robert, and V. Neirinck, "Determination of hydroxyl groups in lignins evaluation of 1H-, 13C-, 31P-NMR, FTIR and wet chemical methods," Holzforschung, vol. 48, no. 5, pp. 387-394, 1994.

[57] M. Cochet, G. Louarn, S. Quillard, M. I. Boyer, J. P. Buisson, and S. Lefrants, "Theoretical and experimental vibrational study of polyaniline in base forms: nonplanar analysis," Journal of Raman Spectroscopy, vol. 31, pp. 1029-1039, 2001.

[58] K. Waleed and N. A. El-Zawawy, "Blended graft copolymer of carboxymethyl cellulose and poly(vinyl alcohol) with banana fiber," Journal of Applied Polymer Science, vol. 100, pp. 1842-1848, 2006.

[59] R. Dhabhai, S. P. Chaurasia, and A. K. Dalai, "Effect of pretreatment conditions on structural characteristics of wheat straw," Chemical Engineering Communications, vol. 200, no. 9, pp. 1251-1259, 2013.

[60] A. C. H. Barreto, M. M. Costa, A. S. B. Sombra et al., "Chemically modified banana fiber: structure, dielectrical properties and biodegradability," Journal of Polymers and the Environment, vol. 18, no. 4, pp. 523-531, 2010.

[61] M. Lu, J. Li, L. Han, and W. Xiao, "High-solids enzymatic hydrolysis of ball-milled corn stover with reduced slurry viscosity and improved sugar yields," Biotechnology for Biofuels, vol. 13, no. 1, p. 77, 2020.

[62] Y. Sun and J. Cheng, "Hydrolysis of lignocellulosic materials for ethanol production: a review," Bioresource Technology, vol. 83 , no. 1 , pp. 1-11, 2002.

[63] E. Abraham, B. Deepa, L. A. Pothan et al., "Extraction of nanocellulose fibrils from lignocellulosic fibres: a novel approach," Carbohydrate Polymers, vol. 86, pp. 1468-1475, 2010.

[64] F. L. Shimizu, P. Q. Monteiro, P. H. C. Ghiraldi et al., "Acid, alkali and peroxide pretreatments increase the cellulose accessibility and glucose yield of banana pseudostem," Industrial Crops and Products, vol. 115, pp. 62-68, 2018.

[65] J. B. Kristensen, C. Felby, and H. Jørgensen, "Yield-determining factors in high-solids enzymatic hydrolysis of lignocellulose," Biotechnology for Biofuels, vol. 2, no. 1, p. 11, 2009.

[66] T. K. Ghose, "Application of a cellulase enzyme system and an integrated process for biomass conversion into ethanol," in Biochemical Engineering for 2001, S. Furusaki et al., Ed., Springer-Verlag, Tokyo, Japan, pp. 711-718, 1992.

[67] E. V. Chidi, S. Oluwatisin, and K. Deborah, "Microwave-alkaline assisted pretreatment of banana trunk for bioethanol production," Journal of Energy and Power Engineering, vol. 9, pp. 705-713, 2015.

[68] S. A. Alrumman, "Enzymatic saccharification and fermentation of cellulosic date palm wastes to glucose and lactic 
acid," Brazilian Journal of Microbiology, vol. 47, no. 1, pp. 110-119, 2016.

[69] H. Xu, B. Li, and X. Mu, "Review of alkali-based pretreatment to enhance enzymatic saccharification for lignocellulosic biomass conversion," Industrial \& Engineering Chemistry Research, vol. 55, no. 32, pp. 8691-8705, 2016.

[70] D. P. Maurya, A. Singla, and S. Negi, "An overview of key pretreatment processes for biological conversion of lignocellulosic biomass to bioethanol," 3 Biotech, vol. 5, no. 5, pp. 597-609, 2015.

[71] H. S. Oberoi, P. V. Vadlani, L. Saida, S. Bansal, and J. D. Hughes, "Ethanol production from banana peels using statistically optimized simultaneous saccharification and fermentation process," Waste Management, vol. 31, no. 7, pp. 1576-1584, 2011.

[72] Kusmiyati and R. P. Sukmaningtyas, "Pretreated of banana pseudo-stem as raw material for enzymatic hydrolysis and bioethanol production," MATEC Web of Conferences, vol. 154, Article ID 01035, 2018. 